\title{
Effects of nanoscale zerovalent cobalt on growth and photosynthetic parameters of soybean Glycine max (L.) Merr. DT26 at different stages
}

\author{
Dang Diem Hong ${ }^{1 *}$, Hoang Thi Lan Anh'1 , Luu Thi Tam', Pau Loke Show ${ }^{2}$ and Hui Yi Leong ${ }^{2}$
}

\begin{abstract}
Nowadays, nanotechnology is one of the most potential tools in the modern agriculture to improve productivity, adaptation to climate change and sustainable development. In this study, the effect of nanoscale zerovalent cobalt (NZVC) on the growth, photosynthetic parameters expressed by Fo (initial fluorescence), Fm (maximal fluorescence), $\mathrm{Fv} / \mathrm{Fm}$ (maximal photochemical efficiency), $\Phi_{\text {PSII }}$ (effective quantum yield of photosystem II), ETR (photosynthetic electron transport rate), $\mathrm{Pn}$ (net photosynthetic rate) and content of chlorophyll a and b at different stages in soybean leaves were investigated. The NZVC made from Vietnam and USA with different concentrations $(0,0.17$ and $16.7 \mathrm{mg} / \mathrm{kg}$ seed) were used. It was found that when soybean seeds were treated with NZVC, the growth indices (such as the plant height, dry weights of stems and leaves and leaf area), photosynthetic parameters and chlorophyll a and b content were increased obviously compared with that of the control. These values had tended to gradually increase and reach maximum at fifth (V5) trifoliate stage, whereas they were significantly decreased at begin at flowering (R1) stage. The real productivity of the experimental formulas exceeded the control (5\%), while the quality of grain was significant different among the plots. The zerovalent cobalt nanoparticle from Vietnam exhibited similar efficiency compared to those that came from USA. Our results indicated that photosynthesis was positively affected by NZVC, leading to the improved growth of soybean and therefore to improved productivity as a whole.
\end{abstract}

Keywords: Nanoscale zerovalent cobalt, Growth stages, Photosynthesis, Soybean

\section{Introduction}

Nanoparticles are typically ultrafine particles with size ranging from 1 to $100 \mathrm{~nm}$ [1]. Nano-technologies are one of the major directions of modern science and technology development which can bring the results comparable to those achieved for the recent decades and in the nearest future [2]. Many fields can be applied nanotechnologies, such as construction materials, microelectronics, optics, power engineering, military art, transport, biotechnologies, medicine, environment protection, and agriculture [3]. In comparison with ordinary substances, nanomaterials possess different physical, chemical and biological properties owing to their smaller size and

\footnotetext{
* Correspondence: ddhong60vn@yahoo.com; ddhong@ibt.ac.vn ${ }^{1}$ Institute of Biotechnology, Vietnam Academy of Science and Technology, 18 Hoang Quoc Viet, Cau Giay, Hanoi, Vietnam

Full list of author information is available at the end of the article
}

high-surface area [4]. They have unique electronic, optical, magnetic and chemical properties and were essential elements in growth and development of plants [5]. So, they were used at an extra low nanocrystalline dose (about $20-80 \mathrm{mg} / \mathrm{ha}$ ), depended on the plant species and metal powder used [6].

Cobalt (Co) plays an essential role in the plant growth development by regulating plant water utilization and reducing transpiration rate, especially, for nodule formation and $\mathrm{N}_{2}$ fixation processes [7]. It is an essential element for the synthesis of various enzymes and coenzymes like vitamin $B_{12}$ (cyanocobalamin), which are required for human and animal nutrition [8]. It activates glycolysis enzyme phosphoglucomutase and arginase which hydrolyze arginine, participates in biosynthesis of leghemoglobin and oxidising processes as well as activates enolase and kinase enzymes in the process of pyruvic acid

(c) The Author(s). 2019 Open Access This article is distributed under the terms of the Creative Commons Attribution 4.0 International License (http://creativecommons.org/licenses/by/4.0/), which permits unrestricted use, distribution, and 
transformation. Co has been shown to affect the growth and metabolism of plants to varying degrees depending on the concentration and status in the rhizosphere. Toxic concentrations of Co can inhibit active transport in plants. At high concentrations, Co causes toxic effects like leaf fall, inhibition of greening, veins discolouring, premature leaf closure and reducing of shoot weight [9]. As a consequence, its dosage is controlled at low amount. According to Hoe et al. [10], when soybean seed (Glycine max (L) Merr.) was treated with Co nanoparticles (at concentration $0.05 \mathrm{mg} / \mathrm{L}$ ) prior sowing, the germination rate, the growth of primary roots and leaves were significantly better than that of control after $39 \mathrm{~h}$ of germination. The root mitotic index of soybean was increased $37.3 \%$ compared to control.

Soybean belongs to Fabaceae family and it is one of the major crops grown worldwide for human consumption [11]. Soybean is an important precursor in elaborating various biomaterials and biodiesel [12]. Moreover, the unsaturated fatty acids, protein, mineral salts and plant secondary metabolites contained in soybeans are crucial for human and animal nutrition [13].

Photosynthesis is an important physiological process in plants that form the basis of their growth and development [14]. Chlorophyll is widely used to analyze photosynthesis because it is related to the photosynthetic activities, although at a complex manner [15]. It can also give an indicaytion of the related protective mechanisms in plants under biotic and abiotic stress [16, 17]. However, up to now, there is no study done on the effects of nanoscale zerovalent cobalt (NZVC) on chlorophyll a fluorescence in plants. In this study, the effects of NZVC on growth (such as the plant height, dry weights of stems and leaves and leaf area) and photosynthetic parameters of soybean plants were studied. These obtained initial results will contribute somewhat to elucidate the physiological and biochemical effect and mechanism of productivity gain of NZVC on plants.

\section{Materials and methods}

\section{Preparation of zerovalent cobalt nanoparticles}

Vietnamese cobalt nanopowder was prepared using the aqueous solution reduction method which based on Ngo et al. [6]. USA cobalt nanopowder used in the study was purchased from US Research Nanomaterials, Inc. (Texas, USA) as positive control. Size of nanocobalt particles was determined by transmission electron microscopy micrographs and $\mathrm{x}$-ray diffraction analysis. After nanocobalt particles was dispersed in solution by sonication, they were in a zerovalent state, particle sizes around from 40 to $60 \mathrm{~nm}$, with their purity $>95 \%[6]$.

\section{Soybean seed treatment}

Soybean seeds cultivar - Vietnamese species DT26 were obtained from Legumes Research and Development Center of Field Crop Research Institute, Vietnam Academy of Agricultural Sciences. A defined amount of nanopowder was dispersed in distilled water and sonicated (375 W, 20 $\mathrm{kHz}$ ) for $4 \mathrm{~min}$. Sodium carboxymethyl cellulose (CMC) was used as a protecting agent and $\mathrm{NaBH}_{4}$ was used as a reducing agent (reduce $\mathrm{Co}^{2+}$ to $\mathrm{Co}^{0}$ ) in the treatment. The experimental formulas for cobalt nanopowder treatment consisted of: (i) control - no NZVC treatment, using distilled water; (ii) $0.17 \mathrm{mg}$ of Vietnamese $\mathrm{NZVC} / \mathrm{kg}$ of seed (CoVN-1); (iii) $16.7 \mathrm{mg}$ of Vietnamese $\mathrm{NZVC} / \mathrm{kg}$ of seed (CoVN-2); (iv) $0.17 \mathrm{mg}$ of USA NZVC/kg of seed (CoUSA1); (v) $16.7 \mathrm{mg}$ of USA NZVC/kg of seed (CoUSA-2). These concentrations of NZVC were used because they were tested in the agar medium at petri dish for the highest stimulatory and inhibitory effects. Specifically, the germination rate, shoot length and chlorophyll content of 0.17 of $\mathrm{NZVC} / \mathrm{kg}$ of seed increased by $3-7 \% ; 2 \mathrm{~cm}-3 \mathrm{~cm}$ and $7-$ $18 \%$ in comparison with the control samples, respectively. These parameters at a concentration of 16.7 of $\mathrm{NZVC} / \mathrm{kg}$ of seed were significantly decreased compared with the control. The number of soybean seeds in each formula were 30 seeds. Soybean seeds were immersed in this suspension for $45 \mathrm{~min}$. After being removed from the petri dishes and dried in air at room temperature, treated seeds were ready for sowing experiments.

\section{Pot trials}

Soils for the pot trial were collected from the rotational crop field of Field Crop Research Institute, Thanh Tri, Ha Noi. Chemical characteristics of the soil for culturing were determined by the Central Analysis Laboratory, Soil and Fertilizer Research Institute (Table 1). The pot trials were carried out in triplicate in a net house under natural light conditions. The treated seeds were planted in each plastic pots $(50 \mathrm{~cm} \times 20 \mathrm{~cm} \times 15 \mathrm{~cm})$ after adding fertilizers (organic-microorganisms fertilizer: $\mathrm{N}: \mathrm{P}_{2} \mathrm{O}_{5}: \mathrm{K}_{2} \mathrm{O}=300: 10: 20: 10 \mathrm{~g} / \mathrm{m}^{2}$ ), watered with distilled water daily.

\section{Measurement of the growth indices}

Samples were collected in four stages: first (V1), third (V3), fifth (V5) trifoliate and begin at flowering stages (R1), corresponding to $10,30,40$ and 50 days after sowing, respectively. The growth indices include the plant height, dry weight of stems and leaves as well as leaf area. Plant height was measured with a ruler. Leaf area was measured by CI-202 Portable Laser Leaf Area Meter (USA). Dry weights of leaves and stems were determined after drying at $80^{\circ} \mathrm{C}$ to attain a constant weight. The productivity of soybean DT26 was accurately calculated after harvesting. 
Table 1 Chemical characteristics of the soil for culturing soybean plant

\begin{tabular}{|c|c|c|c|c|c|}
\hline No. & Parameter & Value & No. & Parameter & Value \\
\hline \multirow[t]{5}{*}{1.} & Soil texture & & 10. & Bio-available nitrogen (mg N/100 g) & 0.45 \\
\hline & Coarse sand (2-0.2 mm) (\%) & 5.41 & 11. & Total phosphor (\%) & 0.09 \\
\hline & Fine sand (0.2-0.02 mm) (\%) & 62.45 & 12. & Bio-available phosphor $\left(\mathrm{mg}_{2} \mathrm{O}_{5} / 100 \mathrm{~g}\right)$ & 5.97 \\
\hline & Limon (0.02-0.002 mm) (\%) & 21.28 & 13. & Total potassium (\%) & 0.92 \\
\hline & Clay $(<0.002 \mathrm{~mm})$ & 10.86 & 14. & Bio-available potassium (mg $\mathrm{K}_{2} \mathrm{O} / 100 \mathrm{~g}$ ) & 16.39 \\
\hline 2. & Gravity $\left(\mathrm{g} / \mathrm{cm}^{3}\right)$ & 2.01 & 15. & Total iron (\%) & 2.80 \\
\hline 3. & $\mathrm{pH}$ & 7.61 & 16. & Total mangan (ppm) & 1241.75 \\
\hline 4. & Salinity (g/L) & 0.68 & 17. & Copper (ppm) & 66.80 \\
\hline 5. & Exchange acidity (meq/100 g) & 0.20 & 18. & Zinc (ppm) & 130.25 \\
\hline 6. & Maximum acidity (meq/100 g) & 3.90 & 19. & Molipden (ppm) & 48.71 \\
\hline 7. & Hydrolysis acidity (meq/100 g) & 3.50 & 20. & Boron (ppm) & 19.02 \\
\hline 8. & Total organic carbon (\%) & 1.66 & 21. & Cobalt (ppm) & 15.03 \\
\hline 9. & Total nitrogen (\%) & 0.11 & & & \\
\hline
\end{tabular}

\section{Determination of chlorophyll content}

Chlorophyll content was analyzed as described in the report of Lichtenthaler [18]. Fresh soybean leaves with $80 \%$ acetone was grounded in a mortar and pestle. The extract was centrifuged at $12,000 \mathrm{rpm}$ for $5 \mathrm{~min}$. Then the absorbance of the supernatant in the wavelength of $470\left(\mathrm{~A}_{470}\right), 646\left(\mathrm{~A}_{640}\right)$ and $663\left(\mathrm{~A}_{663}\right) \mathrm{nm}$ was read by spectrophotometer to determine the content of chlorophylls a $(\mathrm{Ca})$, chlorophyll $\mathrm{b}(\mathrm{Cb})$ and carotenoid $\left(\mathrm{C}_{\mathrm{x}+\mathrm{c}}\right)$. The concentration of photosynthetic pigments was calculated using the following equations:

$$
\begin{aligned}
& \mathrm{Ca}(\mu \mathrm{g} / \mathrm{mL})=12.21 \mathrm{~A}_{663}-2.81 \mathrm{~A}_{646} \\
& \mathrm{Cb}(\mu \mathrm{g} / \mathrm{mL})=20.13 \mathrm{~A}_{646}-5.03 \mathrm{~A}_{663} \\
& \mathrm{Cx}+\mathrm{c}(\mu \mathrm{g} / \mathrm{mL})=\left(1000 \mathrm{~A}_{470}-3.27 \mathrm{Ca}-104 \mathrm{Cb}\right) / 198
\end{aligned}
$$

\section{Measurement of the net photosynthetic rate $(\mathrm{Pn})$}

The Pn was measured by using a portable photosynthetic system (Licor-6400, USA) at 10:00 am under the cultured condition of soybean at $25 \pm 5{ }^{\circ} \mathrm{C}, 300 \mu \mathrm{mol} / \mathrm{m}^{2} /$ s, 370 ppm $\mathrm{CO}_{2}$ and $60 \%$ relative humidity.

\section{Measurements of chlorophyll a fluorescence parameters}

The measurements of chlorophyll a fluorescence parameters were carried out with a OS-30 Chlorophyll fluorometer (ADC, UK). The specific process has been reported by Nguyen et al. [19]. The time of dark adaptation was $7 \mathrm{~min}$ and a high intensity pulses (500-3000 $\mu \mathrm{E})$ of light was used to determine maximal fluorescence (Fm). The Fo is the fluorescent when the reaction center of photosystem II (PSII) are all open. Minimal fluorescence in the light-adapted state (Fo) was determined immediately after turning off the actinic source in the presence of a far-red $(>710 \mathrm{~nm})$ background for $10 \mathrm{~s}$ to ensure maximal oxidation of PSII electron acceptors. The maximal photochemical efficiency $(\mathrm{Fv} / \mathrm{Fm}=($ Fm - Fo)/Fm) was calculated according to the report of Kitajima and Buter [20]. The effective PSII quantum yield $\left(\Phi_{\text {PSII }}\right)$, photosynthetic electron transport rate (ETR) were determined as described in the report of Qiu et al. [16].

\section{Analysis of carbohydrate, protein and lipid contents of soybean seeds}

Moisture, lipids, protein, fiber and ash contents were determined according to the methods recommended by AOAC [21]. The carbohydrate content was calculated as follow:

$$
\begin{aligned}
& \% \text { carbohydrate }=100-(\% \text { protein }+\% \text { lipid }+\% \text { ash } \\
&+\% \text { fiber }+\% \text { moisture })
\end{aligned}
$$

\section{Theoretical productivity of soybean}

$$
\begin{aligned}
& \text { Theoretical productivity (tone } / \text { ha }) \\
& =\frac{\left(\text { Density }\left(\text { plant } / \mathrm{m}^{2}\right) \times \text { Fruits } / \text { Plant } \times \text { Seeds } / \text { fruit } \times \mathrm{P}_{1000} \text { seeds }(\mathrm{g})\right)}{100000}
\end{aligned}
$$

\section{Statistical analysis}

The significance difference between the different treatments was analyzed by one-way analysis of variance (ANOVA). Student's $t$-test was applied to determine the significance between different treatments $(p<0.05)$. 


\section{Results and discussion}

The effect of NZVC on the growth of DT26 soybean plants Table 2 shows the growth indices of soybean plants treated with different concentrations of NZVC on the growth periods. The advantages NZVC are low toxic compared to the salts and chelates, enhancement of physiological and biochemical processes in plants. Sonication of NZVC before the treatment of seeds is important, because NZVC in their pure form do not exhibit biological activity, but in solution after ultrasonic treatment, the active atoms appearing on their surface will be oxidized, giving free electrons. These electrons were used for stimulating metabolic processes (like respiration and sprouting processes in which required free electrons for carrying out their exchange reactions) [6]. When the soybean plants were treated with $0.17 \mathrm{mg}$ of $\mathrm{NZVC} / \mathrm{kg}$ of seesds, the plant height, dry weight of stems and leaves as well as leaf area of soybean plants were increased by $5.70,2.49,18.27,20.76 \%$ at V1 stage; 16.67, $84.21,18.37,22.02 \%$ at V3 stage; 33.33, 10.00, 27.43, $38.27 \%$ at V5 stage and $8.10,25.25,7.16,6.15 \%$ at R1 stage, respectively, compared to the control. These results indicated that the nanoparticles had a positive effect on the growth of soybean at vegetative growth stages. The obtained results also showed the efficiency of NZVC which is originated from Vietnam was similar to that of the USA. Our findings are in agreement with Gad et al. [22] which reported that the cobalt supplement significantly improved all the growth parameters of soybean, such as plant height, leaf area, both the dry weight of stems and leaves especially at $12 \mathrm{mg} / \mathrm{L}$. Similar results also reported by Jayakumar et al. [23] who added the cobalt at $50 \mathrm{mg} / \mathrm{kg}$ of soil increased all the growth parameters compared with the control. These results are in agreement with Gad [24] who found the stimulation effect of cobalt on the plant metabolism and endogenous plant hormones like auxins and gibberellins which increase the growth compared with control.

\section{The effect of NZVC on the photosynthetic pigment contents} in DT26 soybean leaves at different stages

The photosynthetic activity depends on the ability to capture light and the efficiency of conversion of intercepted light into biomass [25]. Leaf photosynthetic rate is related to chlorophyll content [26]. Chlorophyll a is essential to determine photosynthesis. The chlorophyll a and carotenoid contents in soybean leaves treated with NZVC at different stages are shown in Fig. 1. We observe a gradual increase in chlorophyll a, reaching a maximal value of V5 stage. A significant reduction at R1

Table 2 The effect of NZVC on the growth indices of soybean plants at different stages

\begin{tabular}{|c|c|c|c|c|c|}
\hline Stage & Formula & Plant height $(\mathrm{cm})$ & Dry weight of stems (g) & Dry weight of leaves (g) & Leaf area $\left(\mathrm{cm}^{2}\right)$ \\
\hline \multirow[t]{5}{*}{$\overline{V 1}$} & Control & $8.90 \pm 0.16$ & $0.06 \pm 0.02$ & $0.03 \pm 0.00$ & $113.60 \pm 9.85$ \\
\hline & CovN-1 & $9.83 \pm 0.36^{*}$ & $0.07 \pm 0.02$ & $0.04 \pm 0.00^{*}$ & $122.80 \pm 16.30$ \\
\hline & CovN-2 & $11.83 \pm 0.37^{*}$ & $0.07 \pm 0.05$ & $0.04 \pm 0.00^{*}$ & $114.90 \pm 15.70$ \\
\hline & CoUSA-1 & $10.16 \pm 0.6^{*}$ & $0.07 \pm 0.01$ & $0.03 \pm 0.00^{*}$ & $116.40 \pm 11.70$ \\
\hline & COUSA-2 & $11.50 \pm 0.25^{*}$ & $0.08 \pm 0.03$ & $0.04 \pm 0.00^{*}$ & $114.50 \pm 13.60$ \\
\hline \multirow[t]{5}{*}{ V3 } & Control & $24.50 \pm 0.98$ & $0.29 \pm 0.08$ & $0.45 \pm 0.11$ & $205.90 \pm 27.90$ \\
\hline & CoVN-1 & $27.16 \pm 1.16^{*}$ & $0.53 \pm 0.10^{*}$ & $0.50+0.08$ & $257.60 \pm 18.70^{*}$ \\
\hline & CoVN-2 & $26.50 \pm 1.29^{*}$ & $0.36 \pm 0.08^{*}$ & $0.45 \pm 0.12$ & $242.50 \pm 35.10$ \\
\hline & CoUSA-1 & $27.33 \pm 1.15^{*}$ & $0.50 \pm 0.11^{*}$ & $0.47 \pm 0.05$ & $277.00 \pm 28.20^{*}$ \\
\hline & CoUSA-2 & $28.50 \pm 1.78^{*}$ & $0.54 \pm 0.12^{*}$ & $0.51 \pm 0.09$ & $250.80 \pm 15.70$ \\
\hline \multirow[t]{5}{*}{ V5 } & Control & $30.16 \pm 0.40$ & $2.11 \pm 0.12$ & $0.57 \pm 0.07$ & $307.50 \pm 21.50$ \\
\hline & CoVN-1 & $35.67 \pm 1.06 *$ & $2.61 \pm 0.19^{*}$ & $0.72 \pm 0.06^{*}$ & $350.90 \pm 21.10^{*}$ \\
\hline & CoVN-2 & $31.33 \pm 0.25^{*}$ & $2.42 \pm 0.13^{*}$ & $0.62 \pm 0.08^{*}$ & $344.20 \pm 22.50^{*}$ \\
\hline & CoUSA-1 & $32.00 \pm 0.86^{*}$ & $2.79 \pm 0.18^{*}$ & $0.78 \pm 0.09^{*}$ & $362.80 \pm 18.70^{*}$ \\
\hline & CoUSA-2 & $31.50 \pm 0.52^{*}$ & $2.41 \pm 0.17^{*}$ & $0.69 \pm 0.05^{*}$ & $339.70 \pm 20.10^{*}$ \\
\hline \multirow[t]{5}{*}{ R1 } & Control & $34.20 \pm 2.91$ & $2.77 \pm 0.31$ & $0.81 \pm 0.21$ & $377.40 \pm 22.10$ \\
\hline & CoVN-1 & $41.30 \pm 3.01^{*}$ & $3.38 \pm 0.32^{*}$ & $1.12 \pm 0.24$ & $400.60 \pm 18.20$ \\
\hline & CoVN-2 & $35.70 \pm 1.51$ & $3.08 \pm 0.24$ & $0.88 \pm 0.19$ & $394.40 \pm 23.80$ \\
\hline & CoUSA-1 & $38.30 \pm 2.81$ & $3.28 \pm 0.28$ & $1.06 \pm 0.13$ & $411.10 \pm 15.70$ \\
\hline & CoUSA-2 & $36.40 \pm 1.82$ & $3.18 \pm 0.41$ & $0.86 \pm 0.12$ & $388.90 \pm 12.10$ \\
\hline
\end{tabular}

Values are means \pm standard deviation, * Indicate significant difference at $p<0.05$, respectively, between treatments and control; V1, V3, V5 and R1 were first, third, fifth trifoliate and begin at flowering stages, respectively; control - no NZVC treatment, using distilled water; CoVN - 1, 2 and CoUSA - 1, 2: Seeds were treated with 0.17 and $16.7 \mathrm{mg} / \mathrm{kg}$ seeds of Vietnamese and USA NZVCs, respectively 


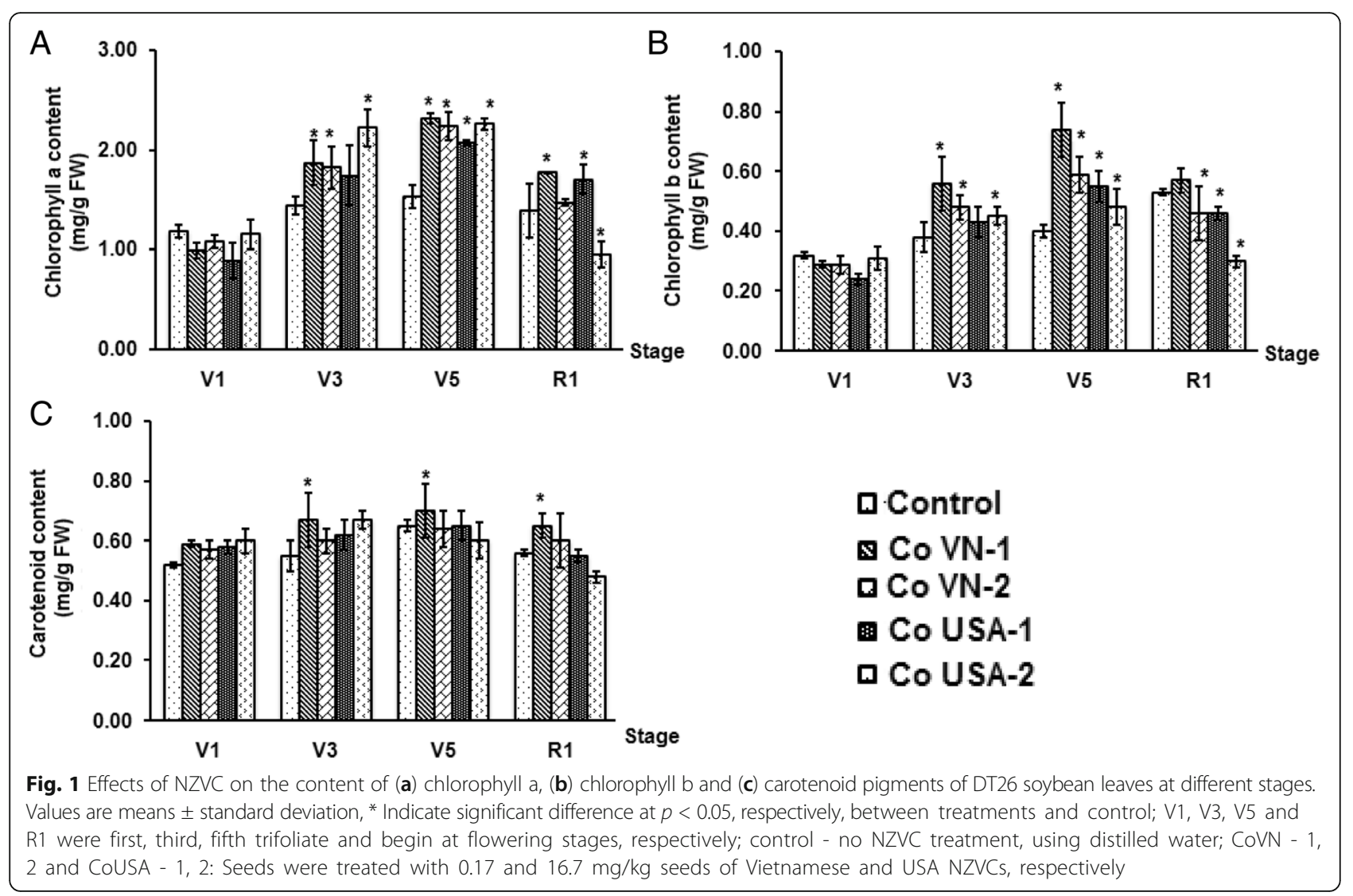

stage followed thereafter. Chlorophyll a content was obviously increased by $35-50 \%$ compared to that of the control when the soybean seeds were treated with NZVC. By using a dose of $0.17 \mathrm{mg}$ of NZVC/ $\mathrm{kg}$ of seeds $(\mathrm{CoVN}-1)$ at V5 stage, we were able to achieve a maximum chlorophyll a of $2.31 \mathrm{mg} / \mathrm{g}$ fresh weight (FW). There were statistically significant differences between chlorophyll a values in the control and different experimental formulas treated by NZVC from V3 to R1 stages (Fig. 1a). However, no statistically significant differences in chlorophyll a values between CoVN and CoUSA at all stages of soybean seedlings $(p>0.05)$. Similar trend was observed in the chlorophyll b content of soybean leaves in the control and treated experimental formulas (CoVN-1, CoVN-2, CoUSA-1, CoUSA-2) (Fig. 1b). The carotenoid content of the soybean leaves in the control and treated experimental formulas has tend to be stable at different growth stages (Fig. 1c). Conforming to Abdul Jaleel et al. [27], photosynthetic pigments, such as chlorophyll a, chlorophyll b, total chlorophyll and carotenoid content of Vigna radiata leaves were increased at lower cobalt concentration $(50 \mathrm{mg} / \mathrm{kg})$, while at higher ones they were decreased. This was due to the cobalt inhibited the activity of the enzymes involve in the synthesis of chlorophyll, such as 5-aminolevulinic acid and protoporphyrin [28]. In addition, high concentration of heavy metals could cause oxidative stress or damage like peroxidation on the chloroplast membrane [29]. However, Ali et al. [30] has reported that the $\mathrm{CoCl}_{2}$ significantly decreased total leaf chlorophyll content of chickpea (Cicer arietinum L.). The $\mathrm{CoCl}_{2}$ at 10 or $20 \mu \mathrm{M}$ exhibited elevated levels of total leaf chlorophyll, whereas higher $\mathrm{CoCl}_{2}$ concentrations $(30-50 \mu \mathrm{M})$ had no effect.

\section{The effect of NZVC on the photosynthetic parameters of} DT26 soybean leaves at different stages

During light reaction, photosynthetic energy conversion can be indicated by the fluorescence emitted by plants, called chlorophyll. Environtment stressors can affect chlorophyll [31]. Therefore, it is widely used to assess the physiological state of higher plant leaves in agricultural applications as well as in biochemical, physiological and ecological studies [32]. The Pn is the most representative photosynthetic parameter, and it can directly reflect the photosynthetic ability of plants. The Fo is minimum fluorescence yield. The increase of the Fo may be due to D1 damage and reduction of the rate of energy trapping by PSII centres which could result in a physical dissociation of LHCII from the PSII. The ratio of Fv/Fm is regarded as a major chlorophyll a fluorescence parameter, which indicated the the maximum quantum efficiency of photosystem II (PSII) photochemistry and has 
been widely used for early stress detection in plants. The $\mathrm{Fv} / \mathrm{Fm}$ and $\Phi_{\text {PSII }}$ represent the conversion efficiency and PSII's capture efficiency of absorbed primary light energy, respectively, and the decrease in $\mathrm{Fv} / \mathrm{Fm}$ and $\Phi_{\text {PSII }}$ indicates that the injury of PSII reaction center [16]. The ETR mainly reflects the electron transport situation of PSII reaction center and it could be represented with the number and rate of light quanta that were absorbed in the electron transport process [20]. In this study, the effect of NZVC on the chlorophyll a fluorescence parameters $\left(\mathrm{Pn}, \mathrm{Fo}, \mathrm{Fm}, \mathrm{Fv} / \mathrm{Fm}, \Phi_{\mathrm{PSII}}\right.$, ETR) of soybean leaves are shown in Fig. 2.

Our results showed that the Pn, Fm, Fv/Fm, $\Phi_{\mathrm{PSII}}$ and ETR of soybean leaves had all tended to increase and reach the maximal values in the V5 period. At the same time, soybean seedlings treated with NZVC at a dose of $0.17 \mathrm{mg} / \mathrm{kg}$ (CoVN-1 and CoUSA-1) increased in the Pn, $\mathrm{Fm}, \mathrm{Fv} / \mathrm{Fm}, \Phi_{\mathrm{PSII}}$ and ETR value, and were higher compared to that of the control and a dose of $16.7 \mathrm{mg} / \mathrm{kg}$ seeds (CoVN-2 and CoUSA-2). Simultaneously, an increased in the $\mathrm{Pn}, \mathrm{Fm}, \mathrm{Fv} / \mathrm{Fm}, \Phi_{\mathrm{PSII}}$ and ETR value was observed in the soybean seedlings treated with NZVC at a dose of $0.17 \mathrm{mg} / \mathrm{kg}$ (CoVN-1 and CoUSA-1). These were higher compared to that of the control and a dose of $16.7 \mathrm{mg} / \mathrm{kg}$ seeds (CoVN-2 and CoUSA-2). At V5 stage, an increase of $69.20,36.19,12.34,67.19$, and $52.00 \%$ were observed in Pn, Fm, Fv/Fm, $\Phi_{\text {PSII }}$ and ETR, respectively for the soybean seedlings treated with 0.17 $\mathrm{mg} / \mathrm{kg} \mathrm{NZVC} \mathrm{(CoVN-1)} \mathrm{compared} \mathrm{to} \mathrm{those} \mathrm{of} \mathrm{the} \mathrm{con-}$ trol $(p<0.05)$. However, an opposite trend was observed in the change of Fo value. The Fo value at V5 in soybean leave was decreased in $34.27 \%$ compared with those of the control. The decrease in Fo value has been shown the injury of PSII were alleviated when soybean seed was treated by cobalt nanoparticles. The increase in $\mathrm{Fv} / \mathrm{Fm}$ value can result in a decrease in the proton electrochemical potential difference across the thylakoid membrane, resulting in a decrease in non-photochemical quenching in the PSII antennae (this is energy loss in the form of heat) [33]. Thereby, stimulation on PSII electron transport. Sarropoulou et al. [34] reported that the stress generated by cobalt causes a marked reduction in net photosynthetic rate in all the tomato cultivars, which may be a direct outcome of reduced stomatal conductance and
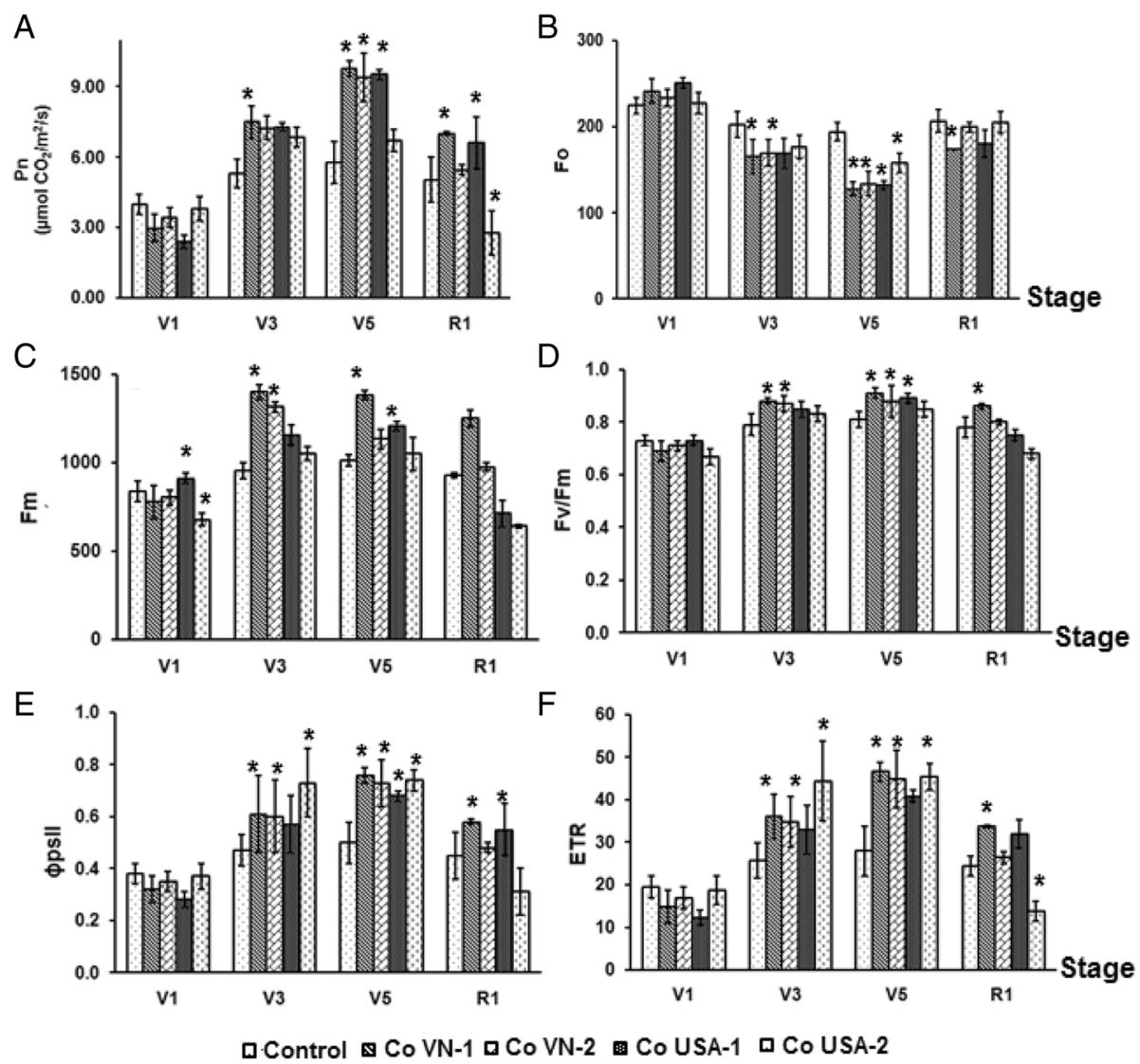

Fig. 2 Changes in photosynthetic parameters of DT26 soybean leaves at different stages as (a) Pn, (b) Fo, (c) Fm, (d) FV/Fm, (e) $\Phi_{\text {PSII }}$ and (f) ETR parameters. Values are means \pm standard deviation, ${ }^{*}$ Indicate significant difference at $p<0.05$, respectively, between treatments and control. V1, V3, V5 and R1 were first, third, fifth trifoliate and begin at flowering stages, respectively; control - no NZVC treatment, using distilled water; CoVN - 1, 2 and CoUSA - 1, 2: Seeds were treated with 0.17 and $16.7 \mathrm{mg} / \mathrm{kg}$ seeds of Vietnamese and USA NZVCs, respectively 
internal $\mathrm{CO}_{2}$ concentration in addition to decreased photosynthetic pigment and activity of carbonic anhydrase. This explained why $\mathrm{Pn}$ value of treated cobalt formula in our experiment at low concentration was higher [34].

Alidoust and Isoda [4] reported that the citrate-coated $\mathrm{Fe}_{2} \mathrm{O}_{3}$ nanoparticles (IONPs-Cit) at $500 \mathrm{mg} / \mathrm{L}$ of concentration significantly enhanced photosynthetic parameters when sprayed foliarly at the eight-trifoliate leaf stage of soybean. The increases in photosynthetic rates following spraying were attributed to increases in stomatal opening rather than increased $\mathrm{CO}_{2}$ uptake activity at the chloroplast level.

\section{The effect of NZVC on productivity and biochemical composition of DT26 soybean}

The effect of NZVC on grain yield and biochemical composition of DT26 soybean was examined, and presented in Table 3. In the same density (30 plants $\left./ \mathrm{m}^{2}\right)$, the productivity parameters of DT26 soybean, such as number fruits/plant, seeds/fruit and $\mathrm{P}_{1000}$ seeds in treated formulas by the NZVC was much different compared to the control. Both the theory and real productivity of soybean seedlings treated by NZVC at different concentrations were higher than that in control $(p<$ 0.05 ). Our results show that growth and productivity of soybean seedlings are promoted by treating with NZVC at the different concentrations $(0.17$ and $16.7 \mathrm{mg} / \mathrm{kg}$ seeds at both CoVN and CoUSA). Real productivity even surpassed the control one by approximately $5 \%$. However, we did not observe any significant differences in real productivity values among the CoVN1, CoVN-2, CoUSA-1, CoUSA-2 $(p>0.05)$. The data showed that all the productivity parameters of both the experimental group of CoVN-1, CoVN-2 and CoUSA-1 and CoUSA-2 were almost the same (Table 3 ).

Therefore, NZVC made from Vietnam was completely quality assurance for agricultural applications. These results are in agreement with Ngo et al. [6] which found that cobalt (at dose $0.08 \mathrm{~g} / \mathrm{ha}$ ) also promoted many developmental processes including germination rates, number of nodules, chlorophyll index and crop yield in soybean (Vietnamese species DT-51). These parameters in experiment sample increased by $45 \% ; 16.93 \% ; 9.63$ and $16.31 \%$ compared to the control sample, repectively. Similarly, Gad et al. [22] who found that the cobalt at $12 \mathrm{mg} / \mathrm{L}$ in plant media increased total seeds yield about $42.5 \%$ in soybean. These data are in concord with those obtained by Balachandar et al. [35] who pointed out that cobalt is a necessary element to legumes, in particular, for nodule formation and nitrogen fixation. Jayakumar [23] has shown that the yield of soybean plant was only increased when treated cobalt at lower concentration. The main advantageous yield was noted only in $50 \mathrm{mg} /$ $\mathrm{kg}$ of cobalt in soil. At higher concentration of cobalt in soil (from 100 to $250 \mathrm{mg} / \mathrm{kg}$ ) there was a marked reduction in yield parameters.

Analytical results of biochemical composition of NZVC-treated soybean grain after harvesting are shown in Table 4. Statistical analysis showed that all the biochemical parameters were statistically significant difference, i.e., in the experimental groups ( $\mathrm{CoVN}$ and CoUSA) and the control sample $(p<0.05)$. Protein and lipid content of experimental groups were higher than that in the control. But carbohydrate content was tended to reverse. These results are similar with those obtained by Gad [36], and revealed that cobalt addition in plant media increased protein, total soluble solids, total carbohydrates and total soluble sugars in groundnut. According to Gad et al. [22], the adding cobalt rate at $12 \mathrm{mg} / \mathrm{L}$ increased the content of proteins $45.4 \%$, total soluble solids $15.6 \%$, total carbohydrates $13.5 \%$ and oil $27.2 \%$ in soybean. The experiments relating to the effects of nanoscale zerovalent cobalt on growth and photosynthetic parameters of soybean Glycine max (L.) Merr. DT26 at different stages was summaried in Additional file 1.

\section{Conclusions}

In summary, nanoscale zerovalent cobalt (NZVC) had positive effects on the soybean growth and development. The real productivity was higher about $5 \%$ at all the experimental formulas treated with NZVC obtained from both the Vietnam and USA in comparison to the control. The growth stimulation of soybean seedlings treated

Table 3 The effect of NZVC on the productivity of soybean plant

\begin{tabular}{lllllll}
\hline Formula & \multicolumn{5}{l}{ Parameters of productivity } \\
\cline { 2 - 7 } & Densityplant/m & Fruits/ plant & Seeds/ fruit & $P_{1000}$ seeds (g) & Theory productivity (tone/ha) & Real productivity (tone/ha) \\
\hline Control & 30 & 24.77 & 1.95 & 165.22 & 2.39 & 2.13 \\
CoVN - 1 & 30 & 27.83 & 2.28 & 176.81 & $3.36^{*}$ & 2.26 \\
CoVN - 2 & 30 & 26.27 & 2.06 & 172.35 & $2.80^{*}$ & 2.20 \\
CoUSA - 1 & 30 & 26.54 & 2.17 & 171.26 & $2.96^{*}$ & 2.22 \\
CoUSA - 2 & 30 & 25.98 & 2.02 & 169.31 & $2.67^{*}$ & 2.22
\end{tabular}

Values are means \pm standard deviation, ${ }^{*}$ Indicate significant difference at $p<0.05$, respectively, between treatments and control. Control - no NZVC treatment, using distilled water; CoVN - 1, 2 and CoUSA - 1, 2: Seeds were treated with 0.17 and $16.7 \mathrm{mg} / \mathrm{kg}$ seeds of Vietnamese and USA NZVCs, respectively 
Table 4 Biochemical composition of the nanocobalt-treated soybean seeds after harvesting

\begin{tabular}{llll}
\hline Formula & Protein (\%) & Lipid (\%) & Carbohydrate (\%) \\
\hline Control & $39.71 \pm 0.25$ & $17.57 \pm 0.06$ & $28.91 \pm 0.11$ \\
CoVN-1 & $40.27 \pm 0.17^{*}$ & $18.68 \pm 0.04^{*}$ & $27.29 \pm 0.10^{*}$ \\
CoVN-2 & $39.61 \pm 0.15^{*}$ & $17.77 \pm 0.10$ & $27.93 \pm 0.09^{*}$ \\
CoUSA-1 & $40.83 \pm 0.11^{*}$ & $17.82 \pm 0.08^{*}$ & $27.41 \pm 0.12^{*}$ \\
CoUSA-2 & $40.27 \pm 0.18^{*}$ & $18.21 \pm 0.05^{*}$ & $27.71 \pm 0.07^{*}$ \\
\hline
\end{tabular}

Values are means \pm standard deviation, *Indicate significant difference at $p<0.05$, respectively, between treatments by NZVC and the control; Control - no NZVC treatment, using distilled water; CoVN - 1, 2 and CoUSA - 1, 2: Seeds were treated with 0.17 and $16.7 \mathrm{mg} / \mathrm{kg}$ seeds of Vietnamese and USA NZVCs, respectively

by NZVC was related to the increase in photosynthesis activity expressed by Pn, Fo, Fm, Fv/Fm, $\Phi_{\text {PSII }}$, ETR parameters. A suitable dose of the NZVC for the treatment of soybean seeds was $0.17 \mathrm{mg} / \mathrm{kg}$ owing to the optimal results. These obtained initial results will contribute to elucidate the mechanism of productivity gain when soybean seed was treated with cobalt nanoparticles.

\section{Additional file}

Additional file 1: Graphical abstract: Summary of experiments relating to the effects of nanoscale zerovalent cobalt on growth and photosynthetic parameters of soybean Glycine max (L.) Merr. DT26 at different stages. In this study, the nanoscale zerovalent cobalt (NZVC) made from Vietnam and USA with different concentrations $(0,0.17$ and $16.7 \mathrm{mg} / \mathrm{kg}$ seed) were used for treatment soybean seeds. The effect of NZVC on the growth, photosynthetic parameters expressed by Fo (initial fluorescence), Fm (maximal fluorescence), $\mathrm{Fv} / \mathrm{Fm}$ (maximal photochemical efficiency), $\Phi_{\mathrm{PSII}}$ (effective quantum yield of photosystem II), ETR (photosynthetic electron transport rate), Pn (net photosynthetic rate) and content of chlorophyll $a$ and $b$ at different stages (V1, V3, V5 and R1) in soybean leaves were investigated. The results have shown that the NZVC treated soybean's growth indices, photosynthetic parameters, and chlorophyll a and b content were increased obviously compared with that of the control. These values reach maximum at fifth (V5) trifoliate stage, whereas they were significantly decreased at begin at flowering (R1) stage. The real productivity of the experimental formulas exceeded the control (5\%), while the quality of grain was significant different among the plots. (TIF $824 \mathrm{~kb}$ )

\section{Abbreviations}

Ca: Chlorophylls a; Cb: Chlorophyll b; Co: Cobalt; $C_{x+c}$ : Carotenoid; ETR: Electron transport rate; Fm: Maximal fluorescence; Fo: Initial fluorescence; Fv/Fm: Maximal photochemical efficiency; NZVC: Nanoscale zerovalent cobalt:

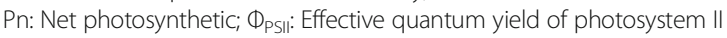

\section{Acknowledgements}

Materials used in this study were kindly provided by Instiutte of Environmental Technology (from Prof. Ngo Quoc Buu, ThS. Dao Trong Hien), Legumes Research and Development Center of Field Crop Research Institute, Vietnam Academy of Agricultural Sciences. Facilities used were kindly offered by National Key Laboratory, Institute of Biotechnology, VAST.

\section{Authors' contributions}

DDH contributed in designing the experiments and drafted sections of abstract, results and discussion. HTLA performed the experiments, drafted Introduction section. LTT performed the experiments, drafted Materials and Methods, References sections. PLS gave comments during contructing manuscipt and revised manuscript. HYL have revised the writing. All authors have read and approved the final manuscript submission.

\section{Funding}

This study was supported by Vietnam Academy of Science and Technology's project (VAST. TĐ. NANO.04/15-18; Assoc. Prof. Nguyen Hoai Chau, and HĐ 22/AD-VCNMT for Assoc. Prof. Dang Diem Hong). Zerovalent cobalt nanoparticle originated from Vietnam/USA and soybean seeds using study were provided by this project. The founding sponsors had no role in the design of the study, in the collection, analyses, or interpretation of data, in the writing of the manuscript, and in the decision to publish the results.

\section{Availability of data and materials}

The datasets used and/or analysed during the current study are available from the corresponding author on reasonable request.

\section{Competing interests}

The co-author Pau Loke Show declared himself as a member of the editorial board of this journal. Other authors declared that they have no competing interests.

\section{Author details}

'Institute of Biotechnology, Vietnam Academy of Science and Technology, 18 Hoang Quoc Viet, Cau Giay, Hanoi, Vietnam. ${ }^{2}$ Department of Chemical and Environmental Engineering, Faculty of Science and Engineering, University of Nottingham Malaysia, Jalan Broga, 43500 Semenyih, Selangor Darul Ehsan, Malaysia.

Received: 7 January 2019 Accepted: 31 May 2019

Published online: 27 June 2019

\section{References}

1. Nowack B, Bucheli TD. Occurrence, behavior and effects of nanoparticles in the environment. Environ Pollut. 2007;150:5-22. https://doi.org/10.1016/j. envpol.2007.06.006

2. Foster L. Nano-Technologies Science, Innovations, Possibilities Moscow TechnoSphere. 2008:352p.

3. Polishchuk SD, Nazarova AA, Kutskir MV, Churilov DG, Ivanycheva IN, Kiryshin VA, Churilov GI. Ecologic-biological effects of cobalt, cuprum, copper oxide nano-powers and humic acids on wheat seeds. Mod Appl Sci. 2015;9:354-64.

4. Alidoust $D$, Isoda A. Effect of $\mathrm{YFe}_{2} \mathrm{O}_{3}$ nanoparticles on photosynthetic characteristic of soybean (Glycine max L. Merr.): foliar spray versus soil amendment. Acta Physiol Plant. 2013;35:3365-75. https://doi.org/10. 1007/s11738-013-1369-8.

5. Ruttkay-Nedecky B, Krystofova O, Nejdl L, Adam V. Nanoparticles based on essential metals and their phytotoxicity. J Nanobiotech. 2017;15:33. https:// doi.org/10.1186/s12951-017-0268-3.

6. Ngo QB, Dao TH, Nguyen GC, Tran XT, Nguyen TV, Khuu TD, Huynh TH. Effects of nanocrystalline powders ( $\mathrm{Fe}, \mathrm{CO}$ and $\mathrm{Cu}$ ) on the germination, growth, crop yield and product quality of soybean (Vietnamese species DT-51). Adv Nat Sci Nanosci Nanotechnol. 2014;5:015016. https://doi.org/10. 1088/2043-6262/5/1/015016

7. DalCorso G, Manara A, Piasentin S, Furini A. Nutrient metal elements in plants. Metallomics. 2014;6:1770-88. https://doi.org/10.1039/c4mt00173g.

8. Collins RN, Kinsela AS. Pedogenic factors and measurements of the plantuptake of cobalt. Plant Soil. 2011;339:499-12. https://doi.org/10. 1007/s11104-010-0584-y.

9. Ayeni OO, Ndakidemi PA, Snyman RG, Odendaal JP. Chemical, biological and physiological indicators of metal pollution in wetlands. Sci Res Essays. 2010:5(15):1938-49.

10. Hoe PT, Mai NC, Lien LQ, Ban NK, Minh CV, Chau NH, Buu NQ, Hien DT, Van NT, Hien LTT, Linh TM. Germination responses of soybean seeds to Fe, ZnO, cu and co nanoparticle treatments. Int J Agric Biol. 2018. https://doi.org/10. 17957/JAB/15.0670

11. López-Moreno ML, de la Rosa G, Hernández-Viezcas JA, Castillo-Michel H, Botez CE, Peralta-Videa JR, Gardea-Torresdey JL. Evidence of the differential biotransformation and genotoxicity of $\mathrm{ZnO}$ and $\mathrm{CeO}_{2}$ nanoparticles on soybean (Glycine max) plants. Environ Sci Technol. 2010;44:7315-20. https://doi.org/10.1021/es903891g.

12. Czernichowski A, Czernichowski M, Wesolowska K. Generation of 1 kg/h of hydrogen from soybean biodiesel. Prepr Pap Am Chem Soc Div Fuel Chem. 2006;51:619-20 
13. Sheykhbaglou R, Sedghi M, Shishevan MT, Sharifi RS. Effects of nano-iron oxide particles on agronomic traits of soybean. Not Sci Biol. 2010;2:112-3. https://doi.org/10.15835/nsb224667.

14. Chia TF, He J. Photosynthetic capacity in Oncidium (Orchidaceae) plants after virus eradication. Environ Exp Bot. 1999;42:11-6. https://doi.org/10. 1016/S0098-8472(99)00010-6.

15. Hussain MI, Reigosa MJ. A chlorophyll fluorescence analysis of photosynthetic efficiency, quantum yield and photon energy dissipation in PSII antennae of Lactuca sativa L. leaves exposed to cinnamic acid. Plant Physiol Biochem. 2011; 49:1290-8. https://doi.org/10.1016/j.plaphy.2011.08.007.

16. Qiu Z, Wang L, Zhou Q. Effects of bisphenol a on growth, photosynthesis and chlorophyll fluorescence in above-ground organs of soybean seedlings. Chemosphere. 2013;90:1274-80. https://doi.org/10.1016/j.chemosphere.2012. 09.085.

17. Guo DP, Guo YP, Zhao JP, Liu H, Peng Y, Wang QM, Chen JS, Rao GZ Photosynthetic rate and chlorophyll fluorescence in leaves of stem mustard (Brassica juncea var. tsatsai) after turnip mosaic virus infection. Plant Sci. 2005;168:57-63. https://doi.org/10.1016/j.plantsci.2004.07.019.

18. Lichtenthaler HK. Chlorophylls and caretonoids pigments of photosynthetic biomembranes. Methods Enzymol. 1987;148:350-82.

19. Nguyen VM, La VH, Ong XP. Methods in plant physiology. Ha Noi (Vietnamese): Vietnam National University Press; 2013.

20. Kitajima M, Butler WL. Quenching of chlorophyll fluorescence and primary photochemistry in chloroplasts by dibromothymoquinone. Biochim Biophys Acta. 1975;376:105-15. https://doi.org/10.1016/0005-2728(75)90209-1.

21. AOAC-Association of offcial analytical chemists. Offcial methods of analysis of the association of Offcial analytical chemists. Arlington, USA. 1990.

22. Gad N, El-Moez A, Bekbayeva LK, Karabayeva AA, Surif M. Effect of cobalt supplement on the growth and productivity of soybean (Glycine max L. Merril). World Appl Sci J. 2013;26:926-33. https://doi.org/10.5829/idosi.wasj. 2013.26.07.13524.

23. Jayakumar K, Abdul Jaleel C, Azooz MM, Vijayarengan P, Gomathinayagam M, Panneerselvam R. Effect of different concentrations of cobalt on morphological parameters and yield components of soybean. GJMS. 2009;4:10-4.

24. Gad N. Increasing the efficiency of nitrogen fertilization through cobalt application to pea plants. Res J Agric Biol Sci. 2006;2:433-42.

25. Confalone A, Lizaso Il, Ruiz-Nogueira B, Lopez-Cedron FX, Sau F. Growth, PAR use efficiency, and yield components of field-grown Vicia faba $\mathrm{L}$. under different temperature and photoperiod regimes. Field Crop Res. 2010;115: 140-8. https://doi.org/10.1016/j.fcr.2009.10.014.

26. Shao Q, Wang $H$, Guo $H$, Zhou A, Huang Y, Sun Y, Li M. Effects of shade treatments on photosynthetic characteristics, chloroplast ultrastructure and physiology of Anoectochilus roxburghii. PLoS One. 2014;9:e85996. https://doi. org/10.1371/journal.pone.0085996.

27. Abdul Jaleel C, Jayakumar K, Chang XZ, Azooz MM. Antioxidant potentials protect Vignaradiata (L.) Wilczek plants from soil cobalt stress and improve growth and pigment composition. Plant Omics J. 2009;2:120-6.

28. Shalygo NV, Kolesnikova NV, Voronetskaya W, Averina NG. Effects of "Mn", "Fe", "CO" and "Ni" on chlorophyll accumulation and early stages of chlorophyll formation in greening barley seedlings. Russ J Plant Physiol. 1999:46:496-01.

29. Clemens S, Palmgren MG, Kramer U. A long way ahead: understanding and engineering plant metal accumulation. Trends Plant Sci. 2002;7:309-15. https://doi.org/10.1016/S1360-1385(02)02295-1.

30. Ali B, Hayat S, Hayat Q, Ahmad A. Cobalt stress affects nitrogen metabolism, photosynthesis and antioxidant system in chickpea (Cicer arietinum L.). J Plant Interact. 2010;5(3):223-31. https://doi.org/10.1080/17429140903370584.

31. Wang XG, Zhao XH, Jiang CJ, Li CH, Cong S, Wu D, Chen YQ, Yu HQ, Wang $\mathrm{CY}$. Effects of potassium deficiency on photosynthesis and photoprotection mechanisms in soybean (Glycine max (L.) Merr.). J Integr Agric. 2015;14:856-63. https:/doi.org/10.1016/S2095-3119(14)60848-0.

32. Ptushenko W, Ptushenko OS, Tikhonov AN. Chlorophyll fluorescence induction, chlorophyll content, and chromaticity characteristics of leaves as indicators of photosynthetic apparatus senescence in arboreous plants. Biochem Mosc. 2014;79:260-72.

33. Maxwell K, Johnson GN. Chlorophyll fluorescence - a practical guide. J Exp Bot. 2000;51:659-68. https://doi.org/10.1093/jexbot/51.345.659.

34. Sarropoulou V, Dimessi- Theriou K, Therios I. Effect of the ethylene inhibitors silver nitrate, silver sulfate, and cobalt chloride on micropropagation and biochemical parameters in the cherry rootstocks CAB-6P and Gisela 6. Turk Biol. 2016;40:670-83. https://doi.org/10.3906/biy-1505-92.
35. Balachandar D, Nagarajan P, Gunasekaran S. Effect of organic amendments and micronutrients on nodulation and yield of blackgram in acid soil. Legume Res. 2003;26:192-5.

36. Gad N. Physiological and chemical response of groundnut (Arachis hypogaea) to cobalt nutrition. World Appl Sci J. 2012;20:327-35. https://doi.org/10.5829/ idosi.wasj.2012.20.02.2818

\section{Publisher's Note}

Springer Nature remains neutral with regard to jurisdictional claims in published maps and institutional affiliations.
Ready to submit your research? Choose BMC and benefit from:

- fast, convenient online submission

- thorough peer review by experienced researchers in your field

- rapid publication on acceptance

- support for research data, including large and complex data types

- gold Open Access which fosters wider collaboration and increased citations

- maximum visibility for your research: over $100 \mathrm{M}$ website views per year

At $\mathrm{BMC}$, research is always in progress.

Learn more biomedcentral.com/submissions 